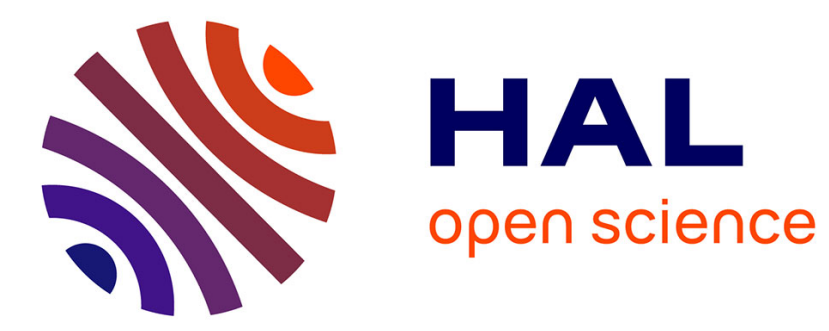

\title{
Shock Behaviour of 3D Carbon-Carbon Composite
} P.-L. Héreil, O. Allix, Michel Gratton

\section{To cite this version:}

P.-L. Héreil, O. Allix, Michel Gratton. Shock Behaviour of 3D Carbon-Carbon Composite. Journal de Physique IV Proceedings, 1997, 07 (C3), pp.C3-529-C3-534. 10.1051/jp4:1997391 . jpa-00255548

\section{HAL Id: jpa-00255548 https://hal.science/jpa-00255548}

Submitted on 1 Jan 1997

HAL is a multi-disciplinary open access archive for the deposit and dissemination of scientific research documents, whether they are published or not. The documents may come from teaching and research institutions in France or abroad, or from public or private research centers.
L'archive ouverte pluridisciplinaire HAL, est destinée au dépôt et à la diffusion de documents scientifiques de niveau recherche, publiés ou non, émanant des établissements d'enseignement et de recherche français ou étrangers, des laboratoires publics ou privés. 


\title{
Shock Behaviour of 3D Carbon-Carbon Composite
}

\author{
P.-L. Héreil, O. Allix* and M. Gratton* \\ Centre d'Études de Gramat, 46500 Gramat, France \\ *École Nationale Supérieure d'Enseignement Technique, 92000 Cachan, France
}

\begin{abstract}
The compressive response of a 3D carbon-carbon composite under shock wave was studied in a plateimpact configuration. Two directions of impact were achieved until a nominal value of longitudinal stress of 2.5 $\mathrm{GPa}$. The measured wave profiles are consistent with previous results on $3 \mathrm{D}$ composites and confirm the behaviour of such materials under impact. It is shown that the initial loading is decomposed in two waves. The first one is transmitted by the longitudinal fibres, the second one corresponds to the propagation of a shock wave in the 'matrix'. Macroscopic characteristics of this material are provided.
\end{abstract}

\begin{abstract}
Résumé . On présente la réponse sous choc d'un composite 3DCC à partir d'essai d'impact de plaques. Deux directions d'anisotropie ont été étudiés jusqu'à une contrainte maximum de 2,5 GPa. La forme des diagrammes de vitesse est cohérente avec les résultats déjà obtenus sur les composites $3 \mathrm{D}$ et confirme leur comportement sous choc. On montre que la sollicitation initiale se décompose en deux ondes. La première est transportée par les fibres longitudinales, la seconde par la matrice. On présente des caractéristiques macroscopiques calculées sur ce composite 3DCC.
\end{abstract}

\section{INTRODUCTION}

The propagation of stress waves has been of considerable interest for several decades, nevertheless its study has been focused principally on homogeneous materials, with much less attention to composites or other heterogeneous materials. Today, composites are increasingly used in aerospace applications and their dynamic behaviour is of considerable interest. Analysis of wave propagation in such materials is interesting but remains a complex problem due to wave reflections and refractions at the fibre-matrix interfaces and to the non-linear response of individual constituents. These complex mechanisms lead to theoretical difficulties in modelling the composite behaviour as pointed out in several papers [1]-[7]. There has been little investigations conducted on transient loading, particularly on the shock wave response of composites and most of them have been focused on the description and characterization of damage under dynamic loading [8]-[13].

The aim of this paper is to study the stress wave propagation in a $3 \mathrm{D}$ carbon-carbon composite (3DCC) up to a longitudinal stress of $2.5 \mathrm{GPa}$. Several results have already been obtained on the global response of 3DCC composites under shock loading. In 1973, Holt et al. [14] presented experimental and theoretical works on 3DCC and ATJ (a homogeneous porous carbon graphite). They proposed an equation of state and a porous model to calculate the thermo-mechanical response of these two materials until a stress of $50 \mathrm{GPa}$. More recently, Mc Queen et al. [15]-[17] and Van Thiel et al. [18] have presented Hugoniot values of 3DCC and porous carbon until a stress of about $100 \mathrm{GPa}$. Goeke and Mc Clintock [19] have examined the failure of 3D graphite composites under shock loading. They observed that the critical element is the fibre bundles oriented in the shock direction.

This work takes part in a more important study which includes the characterization under quasi-static conditions, the recovery of shocked samples in spall experiments and the modelling on a meso-scale of this composite. In this study, our approach is to consider the meso-constituents of the 3DCC composite on both experimental and theoretical point of view. 


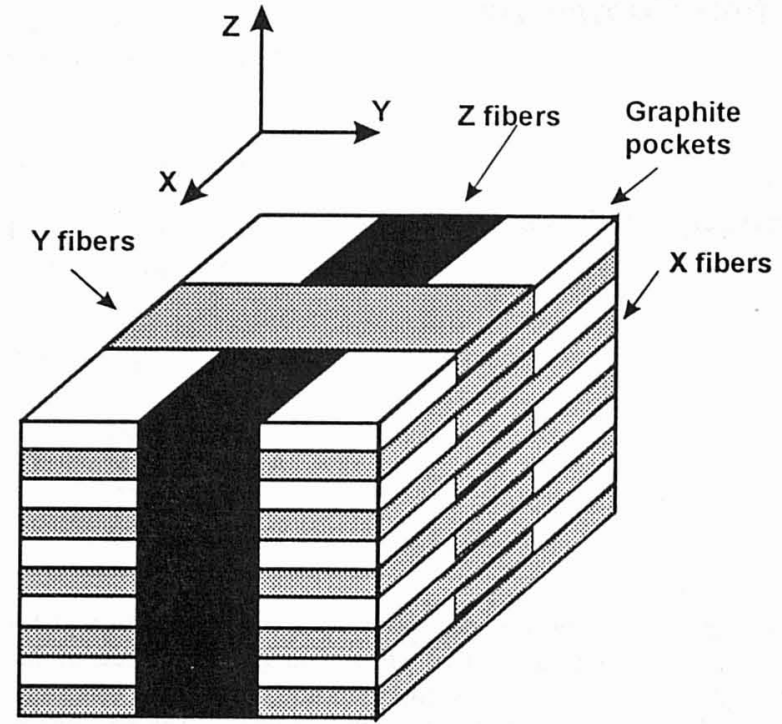

Figure 1 : Schematic of the constituents of $3 \mathrm{DCC}$ composite

\section{Al6061 3DCC PMMA buffer}

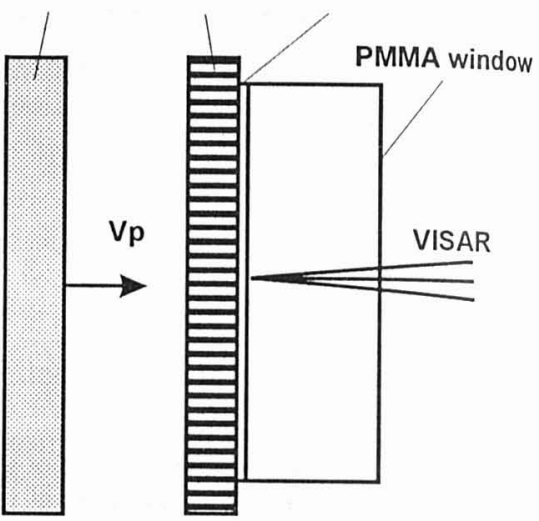

Figure 2: Experimental configuration for dymamic property studies on $3 \mathrm{DCC}$ composite

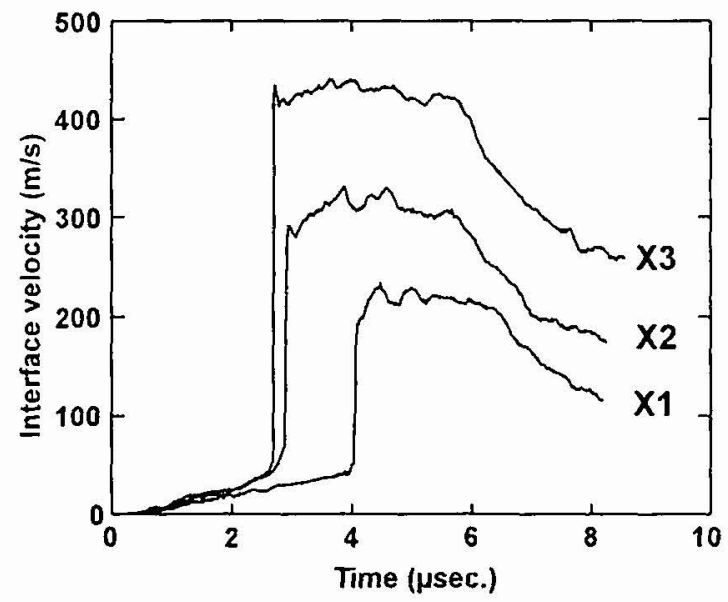

Figure 3 : Interface velocity diagrams obtained on 3DCC composite in the $\mathrm{X}$ direction.

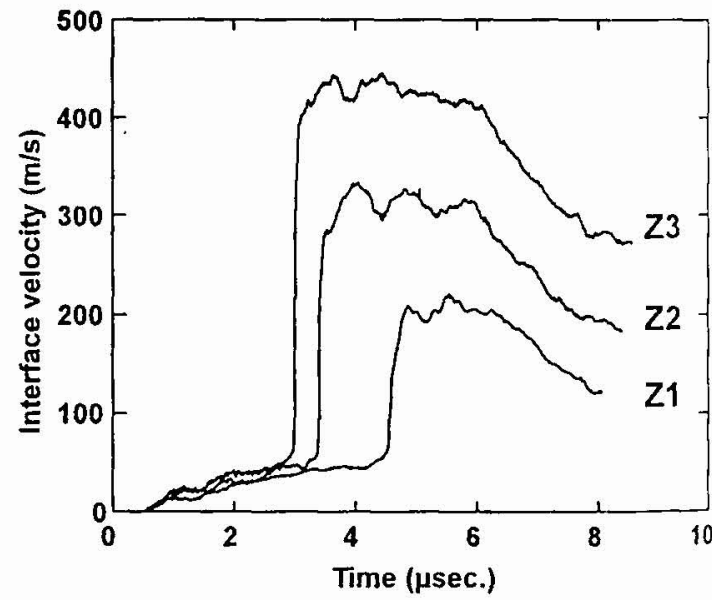

Figure $4:$ Interface velocity diagrams obtained on 3DCC composite in the $\mathrm{Z}$ direction. 


\section{2 - MATERIAL}

The samples of $3 \mathrm{DCC}$ were manufactured by Aérospatiale. They are composed of a $3 \mathrm{D}$ substrate of carbon fibres automatically woven, densified by densification/carbonization cycles and subjected to a final heat treatment at $1200^{\circ} \mathrm{C}$. After this densification, several cracks and voids remain in the samples. The weaving is three orthogonal with a $0.324-\mathrm{mm}$ step in the $\mathrm{Z}$ direction and a $1.6-\mathrm{mm}$ step in both $\mathrm{X}$ and $\mathrm{Y}$ directions which are equivalent (figure 1). Fibres $Z$ are made of 4 wisps of 3000 TORAYCA M-40 filaments. The fibre ratio is $17.7 \%$ in the $Z$ direction and $14.6 \%$ in the $X$ and $Y$ directions.

Composite samples were cut out of disk plates of $60-\mathrm{mm}$ diameter and $8-\mathrm{mm}$ thickness. The cut was made along two different directions : normal to the $Z$ direction and normal to the $X$ direction. All the samples presented a maximum flatness defect of $0.01 \mathrm{~mm}$ and a maximum parallelism defect of $0.02 \mathrm{~mm}$ between their faces.

The mean density of the material is $1.97 \pm 0.03 \mathrm{~g} / \mathrm{cm}^{3}$ which corresponds to a porosity of about $11 \%$. Ultrasonic measurements give a longitudinal velocity of $15570 \pm 300 \mathrm{~m} / \mathrm{s}$ at $15 \mathrm{MHz}$. This value is consistent with results from [20].

\section{EXPERIMENTAL APPROACH}

\subsection{Experimental configuration}

Experiments were conducted at CEG on the 110-mm gas gun DEMETER by using standard plate-impact techniques. The experimental configuration used in the present study is depicted in figure 2 . The target assembly was optically aligned to the barrel axis prior to impact and four flush pins determined impact tilt which was typically less than $1.0 \mathrm{mrad}$. The projectile velocity was measured by three self-shorting pins at the muzzle of the gun, with a relative error of about $0.5 \%$. A VISAR interferometer system [21] was used to measure the particle velocity at the interface between the composite and a transparent window.

A plate of Al606l aluminium alloy impacts the target composed of the 3DCC composite backed by a PMMA buffer and a PMMA window. The buffer is desirable to average the effects of heterogeneities and to provide better survivability of the reflecting surface.

The experimental program has lead to three shots in the $\mathrm{Z}$ direction and three other ones in the $\mathrm{X}$ direction. The experimental parameters are provided in table I and interface velocity profiles in figures 3 et 4. All the profiles show similar characteristics:

- a first compression wave shaped as a ramp: the loading time ranges from $2 \mu s$ to $4 \mu s$ and the maximum intensity from $40 \mathrm{~m} / \mathrm{s}$ to $60 \mathrm{~m} / \mathrm{s}$.

- a second compressive wave corresponding to a shock: its rise time ranges from $8 \mathrm{~ns}$ to $200 \mathrm{~ns}$ and the peak of this wave is proportional to the impact velocity as in homogeneous materials.

- a plateau which shows significant irregularities: the observed oscillations are better marked for the profiles corresponding to the $Z$ direction with an intensity of $30 \mathrm{~m} / \mathrm{s}$ and a period of $850 \pm 100 \mathrm{~ns}$.

- a relatively smooth release wave: its final value corresponds to the difference between the respective impedances of AL6061 impactor, 3DCC target and PMMA window.

\subsection{Interpretation}

The velocity profiles have been analyzed with reference to the results obtained in previous work [22]. In [22], the measurements were carried out with an optical camera and showed the heterogeneous nature of the propagation, as it had been done on an aluminium/epoxy composite [23] and on a 3D quartz phenolic composite [24]. These previous results have shown that longitudinal fibres act as wave guides for a wave propagating in the fibre direction. The initial loading obeys to two propagation modes: the first one 
concerns the longitudinal fibres in which the wave velocity is about $15500 \mathrm{~m} / \mathrm{s}$ and the second one the 'matrix' (the term 'matrix' includes all the other constituents of the composite) in which the wave velocity depends on the intensity of the shock wave. This phenomenon is illustrated in figure 5.

Table I. Parameters of plate-impact experiments on 3DCC composites

\begin{tabular}{cccccc}
\hline $\begin{array}{c}\text { test } \\
\text { number }\end{array}$ & impactor & target & $\begin{array}{c}\text { impactor thickness } \\
(\mathbf{m m})\end{array}$ & $\begin{array}{c}\text { target thickness } \\
(\mathbf{m m})\end{array}$ & $\begin{array}{c}\text { impact velocity } \\
(\mathbf{m} / \mathbf{s})\end{array}$ \\
\hline X1 & Al6061 & 3DCC X / PMMA & 14.96 & $8.09 / 1.00 / 20$ & $269 \pm 1$ \\
X2 & Al6061 & 3DCC X / PMMA & 14.93 & $8.09 / 1.00 / 20$ & $376 \pm 1$ \\
X3 & Al6061 & 3DCC X / PMMA & 14.94 & $8.09 / 1.00 / 20$ & $523 \pm 4$ \\
\hline Z1 & A16061 & 3DCC Z / PMMA & 14.99 & $8.09 / 0.92 / 20$ & $259 \pm 2$ \\
Z2 & Al6061 & 3DCC Z / PMMA & 14.97 & $8.09 / 0.92 / 20$ & $383 \pm 1$ \\
Z3 & Al6061 & 3DCC Z / PMMA & 14.99 & $8.09 / 0.91 / 20$ & $521 \pm 3$ \\
\hline
\end{tabular}

The first ramp wave of the velocity profiles corresponds to the information transmitted by the longitudinal fibres either $\mathrm{X}$ fibres for the experiments $\mathrm{X} 1-\mathrm{X} 3$ or $\mathrm{Z}$ fibres for Z1-Z3. As illustrated in figure 5 , this wave reflects many times on the 3DCC/PMMA interface as well as on the A16061 impact interface before the arrival of the main shock wave which propagates in the 'matrix'. The reverberation of some longitudinal waves are de facto observed on the velocity profiles. This behaviour is more pronounced in the case of $Z$ specimens because their sections and spacings are greater than for $X$ fibres. The role of homogenisation of the compressive waves in the PMMA buffer is significant in this interpretation.

The same interpretation could be done from the oscillations which appear on the plateau of the velocity profiles. Nevertheless, the wave interaction is very complex at this state of deformation and we are not able, at the present time, to evaluate the influence of the PMMA buffer in such conditions. We need further experimental results or numerical simulations with a meso-scaling representation to discriminate the effects of the independent constituents and the influence of the PMMA buffer.

\subsection{Hugoniot calculations}

The heterogeneous nature of deformation in 3DCC composites makes difficult to apply the classical theory of Lagrangian analysis. We have assumed an equivalent homogeneous body in order to calculate the macroscopic characteristics of the shock wave behaviour from the interface velocity profiles. The method is based on the mass and momentum conservation equation and on a graphic representation of the impact location. The Hugoniot state of the target is on the intersection of the Al6061 impactor Hugoniot and of the Rayleigh line calculated with the shock transit time in the 3DCC target. In this analysis, the first ramp wave is considered as a precursor wave and the PMMA behaviour is taken into account to correct the transit time in the buffer.

The results are shown in figures 6-8 in terms of stress, particle velocity, shock wave velocity and specific volume. The error bars were calculated by considering the errors associated with the propagation of the first wave, the behaviour of Al6061 and PMMA, the projectile velocity, the VISAR measurement and the initial density measurement. With the above technique, the values corresponding to the top of the first wave are $0.40 \pm 0.05 \mathrm{GPa}$ for the longitudinal stress and $0.503 \pm 0.001 \mathrm{~g} / \mathrm{cm}^{3}$ for the specific volume.

The relation between particle velocity $u$ and shock wave velocity $D$ is $D=1146+4.07 u$ where $200 \mathrm{~m} / \mathrm{s}<\mathrm{u}<600 \mathrm{~m} / \mathrm{s}$. A comparison with dense graphite Hugoniot [15] (figure 8) indicates that the compaction of 3DCC occurs at the lower longitudinal stress achieved in the experiments. 


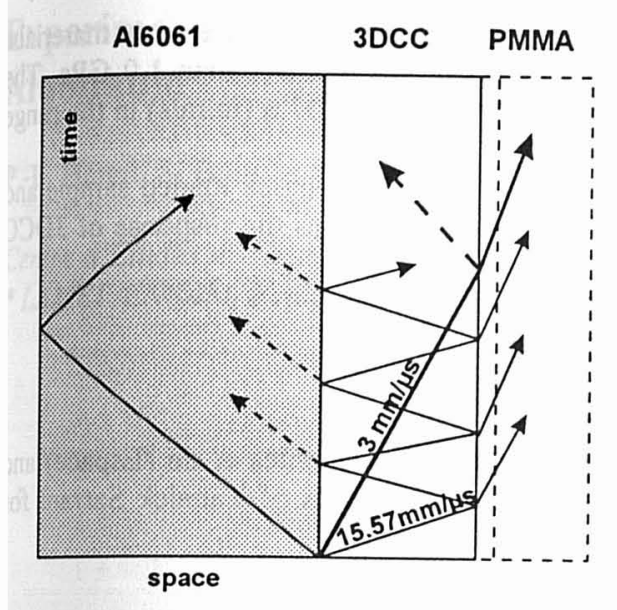

Figure 5 : Schematic characteristic diagram showing the propagation of waves in longitudinal fibers and in the matrix

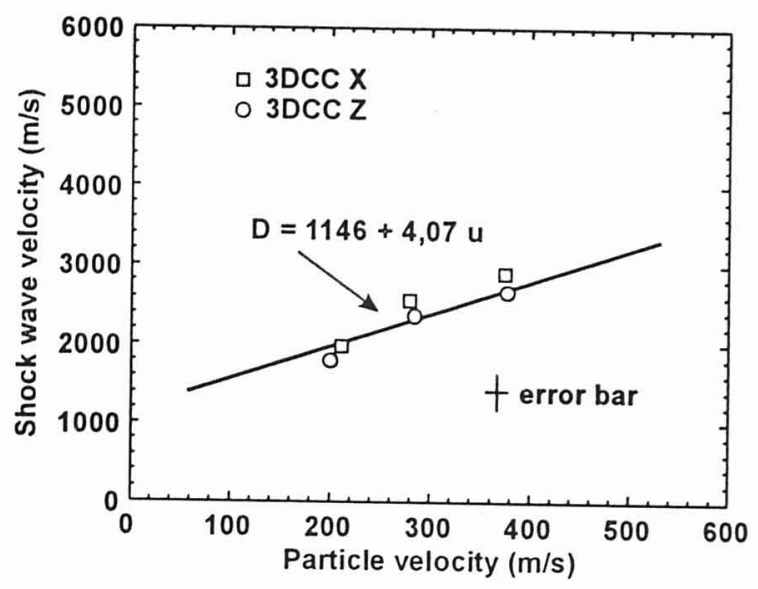

Figure 6 : Shock wave velocity versus particle velocity data for 3DCC composite

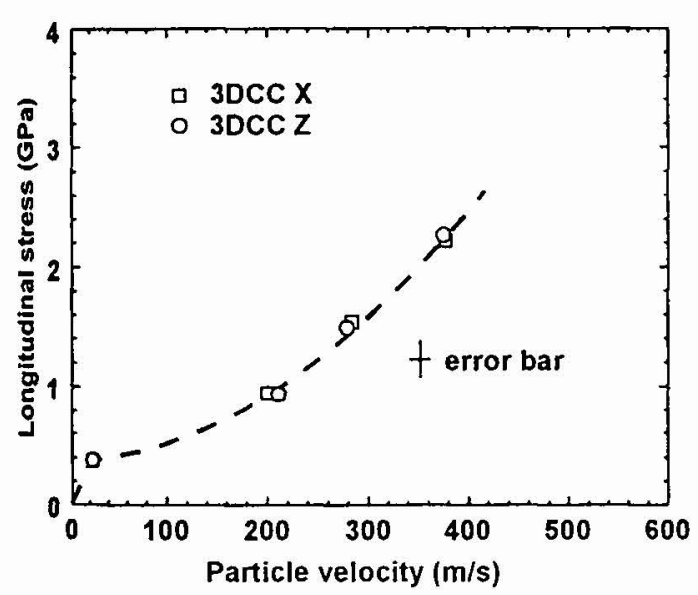

Figure 7 : Hugoniot stress versus particle velocity states for $3 \mathrm{DCC}$ composite

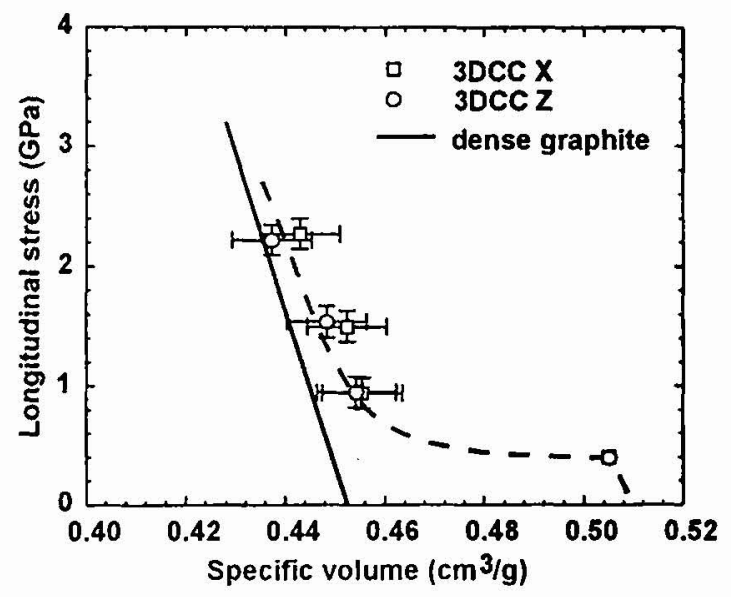

Figure 8 : Dynamic compression stress versus specific volume for $3 \mathrm{DCC}$ composite

\section{CONCLUSION}

The compressive response of a 3DCC composite under shock wave was studied in a plate-impact configuration. A maximum value of longitudinal stress of $2.5 \mathrm{GPa}$ was achieved in two directions of impact: $\mathrm{Z}$ fibre direction and $\mathrm{X}$ fibre direction. The VISAR interferometer provides an accurate measurement of the overall particle velocity profile for impact velocity ranging from $260 \mathrm{~m} / \mathrm{s}$ to $520 \mathrm{~m} / \mathrm{s}$. These velocity profiles are consistent with previous results on $3 \mathrm{D}$ composites and confirms the behaviour of such materials under impact. The initial loading is decomposed in two waves. The first one is transmitted by the longitudinal fibres (either $Z$ or $X$ ), at a wave velocity of about $15500 \mathrm{~m} / \mathrm{s}$ and at a maximum intensity of a few tens of $\mathrm{m} / \mathrm{s}$. The second one corresponds to the propagation of a shock wave in the 'matrix' at a wave velocity depending on the nominal stress. 
The macroscopic values were calculated by a method conventionally used for homogeneous materials. The stress-volume diagram shows that $3 \mathrm{DCC}$ is compacted at a level of stress lower than $1.0 \mathrm{GPa}$. The relation established between shock velocity and particle velocity is $D=1146+4.07 \mathrm{u}(\mathrm{in} \mathrm{m} / \mathrm{s})$ in the range $200-500 \mathrm{~m} / \mathrm{s}$

These results take part in an experimental work which includes recovery of shock loaded sample and quasi static experiments. The ultimate objective is to built a model which describes the response of 3DCC composites at a meso-scale level.

\section{Acknowledgements}

This work was sponsored by the French Ministry of Defense (Direction des Missiles et de l'Espace) and Aérospatiale. The authors would like to gratefully acknowledge the contributions of Yannick Sarrant for shock experiments.

\section{References}

[1] Peck J. C., in Shock Wave and the Mechanical Properties of Solids, Syracuse University Press (1971) p. 155.

[2] Lundergan C.D. and Drumheller D.S., in Shock Wave and the Mechanical Properties of Solids, Syracuse University Press (1971) p. 141.

[3] Barker L.M., J. Comp. Mater., 5 (1971) p. 140.

[4] Curran D.R., Seaman L. and Austin M., J. Comp. Mater, 8 (1974) p. 142.

[5] Bedford A., Mechanics Today, 3 (1976)

[6] Ting T.C.T., Applied Mechanics Reviews, 33, n 12 (1980)

[7] Dumont J.P., Ladeveze P., Poss M. and Remond Y., Composite Structures, 8, (1987) p. 119.

[8] Cohen L.J. and Berkowitz H.M., Journal of the Franklin Institute, 293 (1972) p. 25.

[9] Roylance D., J. Comp. Mater., 14, (1980) p. 111.

[10] Tockeim R.E., Erlich D.C. and Kobayashi T, in Shock Compression of Condensed Matter (1990) p. 473.

[11] O'Donoghue P.E., Anderson C.E., Friesenhahn G.J. and Parr C.H., J. Comp. Mater., 26 (1992) p. 13.

[12] Nemes J.A. and Randles P.W., Mechanics of Materials, 19 (1994) p. 1.

[13] Gupta V., Pronin A. and Anand K., J. Comp. Mater., 30 (1996) p. 722.

[14] Holt A.C., Kusubov A.S., Young D.A. et Gust W.H., Lawrence Livermore Laboratory UCRL-51330 (1973)

[15] LASL Shock Hugoniot Data, S.P. Marsh Editor (1980)

[16] Mc Queen R.G., in Metallurgy at High Pressures and High Temperatures, 22, Gordon and Breach, New York (1964)

[17] Mc Queen R.G. and Marsh S.P., in Behavior of Dense Media under High Dynamic Pressure, Gordon and Breach, New York (1967)

[18] Van Thiel M., Kusubov A.S. et Mitchell A.C., rapport Lawrence Livermore Laboratory UCRL 50108 (1967)

[19] Goeke E.C. and Mc Clintock F.A., J. Appl. Phys., 46 (1975) p. 668.

[20] Baste J.S., Thèse de l'Université de Bordeaux I (1985)

[21] Barker L.M. and Hollenbach R.E., J. Appl. Phys, 41 (1970) p. 4208.

[22] Allix O., Dommanget M., Gratton M. and Hereil P.L., 3ème Colloque National en Calcul des Structures, Giens, France (1997)

[23] Holmes B.S. and Tsou F.K., J. Appl. Phys., 43 (1972) p. 3.

[24] Eden G., Carden M.H., Collyer A.M., and Smith P.M., in Shock Compression of Condensed Matter (1990) p. 217. 